\title{
Historical museum collections and contemporary population studies implicate roads and introduced predatory bullfrogs in the decline of western pond turtles
}

\author{
E. Griffin Nicholson Corresp., 1 , Stephanie Manzo ${ }^{1}$, Zachary Devereux ${ }^{1}$, Thomas Paul Morgan ${ }^{1}$, Robert N. Fisher ${ }^{2}$, \\ Christopher Brown $^{2}$, Rosi Dagit ${ }^{3}$, Peter A. Scott ${ }^{4}$, H. Bradley Shaffer ${ }^{4,5}$ \\ ${ }^{1}$ Institute of the Environment and Sustainability, University of California, Los Angeles, Los Angeles, California, United States of America \\ 2 U.S. Geological Survey, Western Ecological Research Center, San Diego, California, United States of America \\ 3 Resource Conservation District of the Santa Monica Mountains, Topanga, California, United States of America \\ 4 Department of Ecology and Evolutionary Biology, University of California, Los Angeles, Los Angeles, California, United States of America \\ 5 La Kretz Center for California Conservation Science, Institute of the Environment and Sustainability, University of California, Los Angeles, Los Angeles, \\ California, United States of America \\ Corresponding Author: E. Griffin Nicholson \\ Email address: gnicholson@g.ucla.edu
}

The western pond turtle (WPT), recently separated into two paripatrically distributed species (Emys pallida and Emys marmorata), is experiencing significant reductions in its range and population size. In addition to habitat loss, two potential causes of decline are female-biased road mortality and high juvenile mortality from non-native predatory bullfrogs (Rana catesbeiana). However, quantitative analyses of these threats have never been conducted for either species of WPT. We used a combination of historical museum samples and published and unpublished field studies shared with us through personal communications with WPT field researchers (B Shaffer, P Scott, R Fisher, C Brown, R Dagit, L Patterson, T Engstrom, 2019, personal communications) to quantify the effect of roads and bullfrogs on WPT populations along the west coast of the United States. Both species of WPT shift toward increasingly male biased museum collections over the last century, a trend consistent with increasing, female-biased road mortality. Recent WPT population studies revealed that road density and proximity were significantly associated with increasingly male-biased sex ratios, further suggesting female-biased road mortality. The mean body size of museum collections of $E$. marmorata, but not $E$. pallida, has increased over the last 100 years, consistent with reduced recruitment and aging populations that could be driven by invasive predators. Contemporary WPT population sites that co-occur with bullfrogs had significantly greater average body sizes than population sites without bullfrogs, suggesting strong bullfrog predation on small WPT hatchlings and juveniles. Overall, our findings indicate that both species of WPT face demographic challenges which would have been difficult to document without the use of both historical data from natural 
history collections and contemporary demographic field data. Although correlational, our analyses suggest that female-biased road mortality and predation on small turtles by nonnative bullfrogs are occurring, and that conservation strategies reducing both may be important for WPT recovery. 
1 Historical museum collections and contemporary

2 population studies implicate roads and introduced

3 predatory bullfrogs in the decline of western pond turtles

4 E. Griffin Nicholson ${ }^{1}$, Stephanie Manzo ${ }^{1}$, Zachary Devereux $^{1}$, Thomas Morgan ${ }^{1}$, Robert N.

5 Fisher $^{2}$, Chris W. Brown ${ }^{2}$, Rosi Dagit ${ }^{3}$, Peter A. Scott ${ }^{4 *}$, H. Bradley Shaffer ${ }^{4,5 *}$

$7 \quad{ }^{1}$ Institute of the Environment and Sustainability, University of California, Los Angeles, Los

8 Angeles, CA, USA

9 '2U.S. Geological Survey, Western Ecological Research Center, San Diego, CA, USA

$10{ }^{3}$ Resource Conservation District of the Santa Monica Mountains, Topanga, CA, USA

$11{ }^{4}$ Department of Ecology and Evolutionary Biology, University of California, Los Angeles, CA

12 90095, USA

13 5 La Kretz Center for California Conservation Science, Institute of the Environment and

14 Sustainability, University of California, Los Angeles, Los Angeles, CA, USA

15 *indicates equal contribution

16

Email Address: nicholsongriffin502@gmail.com 


\section{Abstract}

44 The western pond turtle (WPT), recently separated into two paripatrically distributed species

45 (Emys pallida and Emys marmorata), is experiencing significant reductions in its range and

46 population size. In addition to habitat loss, two potential causes of decline are female-biased road

47 mortality and high juvenile mortality from non-native predatory bullfrogs (Rana catesbeiana).

48 However, quantitative analyses of these threats have never been conducted for either species of

49 WPT. We used a combination of historical museum samples and published and unpublished field

50 studies shared with us through personal communications with WPT field researchers (B Shaffer,

51 P Scott, R Fisher, C Brown, R Dagit, L Patterson, T Engstrom, 2019, personal communications)

52 to quantify the effect of roads and bullfrogs on WPT populations along the west coast of the

53 United States. Both species of WPT shift toward increasingly male biased museum collections

54 over the last century, a trend consistent with increasing, female-biased road mortality. Recent

55 WPT population studies revealed that road density and proximity were significantly associated

56

57 with increasingly male-biased sex ratios, further suggesting female-biased road mortality. The mean body size of museum collections of E. marmorata, but not E. pallida, has increased over the last 100 years, consistent with reduced recruitment and aging populations that could be driven by invasive predators. Contemporary WPT population sites that co-occur with bullfrogs had significantly greater average body sizes than population sites without bullfrogs, suggesting strong bullfrog predation on small WPT hatchlings and juveniles. Overall, our findings indicate that both species of WPT face demographic challenges which would have been difficult to document without the use of both historical data from natural history collections and contemporary demographic field data. Although correlational, our analyses suggest that femalebiased road mortality and predation on small turtles by non-native bullfrogs are occurring, and that conservation strategies reducing both may be important for WPT recovery.

\section{7}

68

69

70

71

72

73

74

75

76

77

78

79

80

81

82

83

\section{Introduction}

Natural history museum collections are often the only source of historical information for declining and endangered species, and can be an important tool when documenting and analyzing species declines and their causes. Specimen data have primarily been used to determine changes in the distribution of individual species or taxonomic groups (Shaffer et al., 1998; Pyke \& Ehlrich, 2010), often focusing on species of conservation concern (Fisher \& Shaffer, 1996; Grixti et al., 2009; Hamer et al., 2010; Major \& Parsons, 2010; Saarinen \& Daniels, 2012). Although less commonly emphasized, museum collections can also provide historical insights into demographic changes that are important proximate mechanisms of population trajectories and necessary for population viability analyses (PVAs, see McCarthy et al., 1995; Lacy, 2000). This is particularly important for declining species being considered for formal protection, given that such conservation actions often rest on evidence of population trends. If museum collections are unbiased samples of species through time (a strong assumption in many cases), they can provide critical clues about population and demographic histories. For example, museum specimens have recently been utilized for multiple species as evidence of shifts in body size due to climate change (Babin-Fenske et al., 2008; Caruso et al., 2014, Weeks et al., 2019). 
84

85

86

87

88

89

90

91

92

93

94

95

96

97

98

99

100

101

102

103

104

105

106

107

108

109

110

111

112

113

114

115

116

117

118

119

120

121

122

123

124

125

126

127

128

129

We conducted a comprehensive analysis of museum specimens of western pond turtles (WPTs, Fig. 1), a pair of species which is currently petitioned for listing under the U.S. Endangered Species Act (USFWS, 2015). Habitat loss and fragmentation have been identified as major factors associated with population declines in WPTs, particularly in Southern California (Thomson et al., 2016). In addition, perceived, but largely unstudied demographic changes have led to two further hypotheses for the decline of both WPT species.

The first hypothesis centers on observations that the sex ratio of WPT populations is often male-biased (Spinks et al., 2003; Polo-Cavia et al., 2010; although see Germano \& Riedle, 2015), leading to the speculation that terrestrial roadkill mortality has preferentially removed nesting adult females from many populations. In the United States, a relatively recent review of the literature on turtle population sex ratios, published between 1928 and 2003 covering 36 different species, reported an average $22 \%$ increase in the intrapopulation proportion of males, and that this bias was most pronounced in aquatic species (Gibbs \& Steen, 2005). Other studies have found similar increases in male bias in turtle populations (Aresco, 2005; Vanek \& Glowacki, 2019). Although this body of work clearly indicates an increase in male bias across many aquatic turtle species, there is less certainty about the cause of these shifts. Roads and their associated vehicle traffic can have profound impacts on wildlife (Spellerberg, 1998), and studies of other species have suggested that vehicular mortality results in male biased turtle populations near roads (Marchand \& Litvaitis, 2004; Steen \& Gibbs, 2004; Aresco, 2005). Countering this, a study of painted turtles (Chrysemys picta) near Chicago, IL found a large male bias (75\% male), but no evidence of road density as a causal factor (Vanek \& Glowacki, 2019), and a population model predicted that populations of small-bodied pond turtles, like the WPT, should not be threatened by road mortality anywhere in the United States (Gibbs \& Shriver, 2002). In Ontario, Canada, one study of painted turtles found no higher frequency of males at sites closer to major roads than more remote sites further from roads (Dorland et al., 2014). Another study in the Ontario area used long-term data on turtles admitted to the Kawartha Turtle Trauma Centre and found that Midland Painted Turtles (Chrysemys picta marginata), Snapping Turtles (Chelydra serpentina), and Blanding's Turtles (Emydoidea blandingii) did not have significantly biased sex ratios among admissions for road injuries. However, Northern Map Turtle (Graptemys geographica) road injury admissions were significantly female-biased (Carstairs et al., 2018), indicating that the impact of road mortality on sex ratios may differ between sympatric species on the same landscape. Nesting WPTs may be especially vulnerable to vehicular mortality because they can travel hundreds of meters from their aquatic habitats to find nesting sites (Storer, 1930; Holland, 1994). However, evidence for road-proximity caused shifts in sex ratio in the WPT is limited to two reports (Holland, 1994; Madden-Smith et al., 2005), both of which suggest that vehicular traffic may be leading to differential female mortality. A more comprehensive analysis is needed to specifically evaluate the hypothesis that roads are the cause of an increase in male bias in WPTs.

A second hypothesis for the decline of WPTs comes from ecological surveys suggesting reduced juvenile recruitment due to predation by non-native bullfrogs (Lovich et al., 2017; Smith, 2018). American bullfrogs (Rana catesbeiana) are a pervasive invasive species outside of their native eastern U.S. range and are opportunistic predators on many aquatic vertebrates. An examination of bullfrog stomach contents from southern Vancouver Island, British Columbia, Canada found that $6 \%$ of total prey were western painted turtle (C. picta bellii) hatchlings (Jancowski \& Orchard, 2013),demonstrating that these large amphibians regularly consume small turtles in their non-native range. However, in their native range, bullfrogs are sympatric 
130 with most North American turtles, and turtle hatchlings comprise a consistent, but apparently

131

132

133

134

135

136

137

138

139

140

141

142

143

144

145

146

147

148

149

150

151

152

153

154

155

156

157

158

159

160

161

162

163

164

165

166

167

168

169

170

171

minor component of their diet (Bury and Whelan, 1984). At least one study found no evidence of significantly higher bullfrog densities or average individual sizes in introduced populations (Govindarajulu et al., 2006), suggesting that the cause of turtle declines by bullfrogs may be due to the behavior of turtles in historically bullfrog-free regions. Individuals that did not co-evolve with this novel predator may lack appropriate anti-predator responses, particularly in naïve baby turtles that are most susceptible to predation. Invasive bullfrogs are now found across much of the range of the WPT (Fig. S1; Holland, 1994), and documented predation has led several authors to hypothesize that they are responsible for WPT declines and extirpations (Lovich \& Meyer, 2002; Hallock et al., 2017; Lovich et al., 2017; Fig. 2). Hatchlings and small juveniles less than three years old are the most vulnerable to predation by bullfrogs (Hallock et al., 2017). Compelling, but still anecdotal, information on the effect of bullfrogs was highlighted in a study in northwestern California, USA, where four out of six lentic sites near the Trinity River had abundant bullfrog populations and were biased towards large, old WPTs, while two sites lacking bullfrogs did not exhibit this trend (Sloan, 2012). Although much of the research on the impacts of bullfrogs on WPT populations has been anecdotal, the number of studies (Lovich \& Meyer, 2002; Sloan, 2012; Hallock et al., 2017; Lovich et al., 2017) finding a correlation between bullfrog presence and a decrease in juvenile turtles suggests that bullfrogs could be a serious threat to the persistence and viability of WPT populations.

Our goal in this study was to quantitatively assess trends in shifting sex ratios and population demography in WPTs, and the potential roles of road mortality and predation by nonnative American bullfrogs as causal agents (Lovich \& Meyer, 2002; Hallock et al., 2017; Smith, 2018). We analyzed the majority of available museum specimens, combined these historic records with several published and unpublished data sets of contemporary populations shared with us through personal communications with WPT field researchers (B Shaffer, P Scott, R Fisher, C Brown, R Dagit, L Patterson, T Engstrom, 2019, personal communications), and quantified historical trends in the WPT from the earliest to the most current information available. We used these observational data sets to quantify trends in sex ratio and juvenile recruitment over time, and to ask whether road density and the presence of bullfrogs were plausible causal factors responsible for those trends. Although these tests are correlational, our analyses strongly suggest that that road density and bullfrog occupancy may be important causal agents of WPT population declines.

\section{Materials \& Methods}

\section{Taxonomy}

The WPT complex comprises the only extant native freshwater turtles in California (Thomson et al., 2016; Turtle Taxonomy Working Group, 2017). Until recently, the WPT was considered a single polytypic species ranging from Baja California, Mexico to Washington State, USA that has variously been classified in the genus Emys, Actinemys, or Clemmys (Fritz et al., 2011; Turtle Taxonomy Working Group, 2017). The generic assignment of the WPTs is still controversial, with vocal proponents placing the two species in a more inclusive Emys or a more narrowly defined Actinemys (Fritz et al., 2011; Spinks et al., 2016; Turtle Taxonomy Working Group, 2017); we follow Spinks et al., $(2014,2016)$ in recognizing a more inclusive Emys as the

Peer) reviewing PDF | (2019:10:42370:1:1:NEW 4 May 2020) 
172 generic allocation. In addition, recent multi-locus molecular genetic analyses indicate that the

173 WPT consists of two distinct, geographically non-overlapping species: Emys (Actinemys) pallida

174 and E. (A.) marmorata (Spinks et al., 2014). Emys pallida occupies the southern and coastal

175 portion of the range from Baja California to roughly San Francisco Bay, while E. marmorata

176 occupies the inland San Joaquin Valley/Sierra Nevada foothills of Central California north to

177 Washington State (Thomson et al., 2016; Fig. 1). Throughout this paper, when we refer simply

178 to western pond turtles (WPTs) without indicating species, we are considering both of these

179 ecologically similar species. However, for many of our analyses, we disentangle the two species

180 so that each can be evaluated across its range.

\section{Museum Samples}

We surveyed WPT specimens from three museums to assess changes in sex ratios and carapace (shell) length over time. We evaluated a total of 463 individual WPT specimens collected from 44 counties between 1892-2005 (the Natural History Museum of Los Angeles County, Los Angeles, CA ( $\mathrm{n}=55)$, California Academy of Sciences, San Francisco, CA ( $\mathrm{n}=$ $151)$, and Museum of Vertebrate Zoology, Berkeley, CA ( $n=257)$; Fig. 1; Dataset S1). This represents $82 \%$ (463/566) of the available alcohol/ethanol preserved WPT specimens on VertNet (http://portal.vertnet.org/search; search terms Emys/Actinemys/Clemmys pallida/marmorata, alcohol/ethanol, basisOfRecord = PreservedSpecimen [accessed on $2019-08-11])$. We measured midline carapace length for each specimen (Fig. S2; Iverson, 2018) and recorded the sex of each specimen, based on tail length and plastral curvature. Other key information including collection date, county, state, and GPS coordinates were extracted from online museum databases. Using distribution information from the most recent molecular analysis (Spinks et al., 2014), we classified each specimen as either E. pallida $(\mathrm{n}=147)$ or E. marmorata $(\mathrm{n}=316)$ based on its county of origin (Fig. 1, Table S1).

196

197

198

199

200

201

202

203

204

205

206

207

208

209

210

211

212

213

\section{Contemporary Samples}

Demographic information for current samples primarily came from unpublished data contributed by WPT field researchers (Fig. 3). For E. pallida, data sets came from trapping data provided by the USGS, San Diego office (R Fisher \& C Brown, 2019, personal communications), the Resource Conservation District of the Santa Monica Mountains, Los Angeles County, CA (R Dagit, 2019, personal communication), Lake Elizabeth, Los Angeles County, CA (B Shaffer, 2019, personal communication) and a trapping survey in the Jack and Laura Dangermond Preserve, Santa Barbara County (B Shaffer \& P Scott, 2019, personal communications). Field tagging and tracking of WPTs in the Santa Monica Mountains was approved by the California Department of Fish and Wildlife (CDFW SC-604). USGS sampling and field tagging of WPTs in Southern California was also approved by the CDFW (CDFW SCP-838). The Nature Conservancy gave permission to sample on the Dangermond Preserve which was also approved by the CDFW (CDFW SC-2480). For E. marmorata, data sets included two sites near Chico, Butte County, CA (T Engstrom, 2019, personal communication), Sacramento County, CA (L Patterson, 2019, personal communication), and the University of California Davis Arboretum, Yolo County, CA (Lambert et al., 2019). We extracted the midline carapace length (a standard index of body size), sex, date of capture, location and population size from each study. 


\section{Sex Ratio}

215

216

217

218

219

220

221

222

223

224

225

226

227

228

229

230

231

232

233

234

235

236

237

238

All turtles with straight-line carapace length less than $110 \mathrm{~mm}$ were considered immature and removed from the sex ratio analysis for both the museum and current samples. This cutoff is the typical size at which WPTs reach sexual maturity and secondary sexual characteristics become apparent (Holland, 1991), although for southern California E. pallida it may be a few mm smaller (Madden-Smith et al., 2005). To quantify changes in sex ratio, we used logistic regression (RStudio Version 1.2.1335; R Studio Team, 2018; R Core Team, 2019) to plot the probability of sex through time for E. pallida and E. marmorata separately. For each species, three analyses were conducted: a historical regression based on the museum samples only, a regression based on only contemporary samples, and a combined regression based on both the museum and current samples. Within the contemporary data sets, which often recorded the same turtle multiple times within and between years, we counted each individual only once per year. We reasoned that across years recaptured individuals should be included in the sex ratio for each year because that individual survived, and therefore contributes to the sex ratio each year.

\section{Carapace Length}

Given that the contemporary data sets had WPTs which were recaptured multiple times, we filtered the data so that each individual was represented only by its most recent capture data. We reasoned that to make the museum and recent data as comparable as possible, we should only use the last capture as an estimate of body size since the museum specimens could be considered the last capture of each preserved turtle. After filtering the contemporary data sets, we combined these data with our museum specimen data.

To quantify changes in carapace length, we used linear regression in R (RStudio Version 1.2.1335; R Studio Team, 2018; R Core Team, 2019) to plot carapace length through time for $E$. pallida and E. marmorata separately. The linear regression was considered significant at a $p$ value $<0.05$ and the adjusted $\mathrm{R}^{2}$ a measure of the variance explained by that relationship.

\section{The effects of Roads on Sex Ratios}

To analyze the effects of roads on sex ratios, we conducted two independent analyses on the same set of WPT population sites. Based on contemporary studies from the last 20 years, we calculated the sex ratios of WPT population studies that included data on at least 10 unique turtles in each field survey or study (Gibbs \& Steen, 2005). Some sites were the subject of longterm monitoring studies, and we used the most recent seven years of data (corresponding to the average number of years to sexual maturity, Belli, 2015) to estimate the sex ratio for these sites. We used the latitude and longitude of each site to create data points in ArcGIS, mapped them to a 2018 USGS topographic map (USGS Topo), and created an aquatic habitat polygon for each site. For a pond or lake, the polygon was simply the extent of the body of water. For a river, creek, or stream, the polygon included the river channel spanning the two most distant turtle captures.

We first analyzed the relationship between population sex ratio and distance to the nearest road. We calculated and plotted the centroid of each aquatic habitat polygon in ArcGIS (ESRI, 2018, Version 10.6.1, Calculate Geometry option); if a centroid was on land, we manually moved it to the nearest edge of the aquatic habitat polygon, and manually measured the 
255

256

257

258

259

260

261

262

263

264

265

266

267

268

269

270

271

272

273

274

\section{5}

276

277

278

279

280

281

282

283

284

285

286

287

288

289

290

291

292

293

shortest straight-line distance from the centroid to the closest road. Centroids that were further than one kilometer from the nearest road were not included in the analysis because the maximum distance that nesting female WPTs have been recorded from water is approximately 400 meters (Storer, 1930; Holland, 1994); although this number is approximate, we reasoned that sites very distant from roads would suffer little or no road mortality. We used linear regression and a "sliding scale t-test", described below, to describe the relationship between population sex ratio and distance to the closest road.

We also analyzed the relationship between population sex ratio and the density of surrounding roads. We used ArcGIS to create a $400 \mathrm{~m}$ buffer surrounding each aquatic habitat polygon. We then created polylines of the roads within the buffer region of each population site, buffered the polyline feature class six meters, and summed the total buffered area. This gave a total road surface area, assuming that each road is two lanes (one in each direction) and is slightly over the $2.7 \mathrm{~m}$ minimum allowable width (U.S. Department of Transportation Federal Highway Administration, 2013). For the three population sites which had multi-lane highways within their $400 \mathrm{~m}$ buffer, we considered the highways as distinct from the road polyline and buffered each based on the actual number of lanes ( $3 \mathrm{~m} / \mathrm{lane})$. After all polyline buffering was complete, the fraction of the $400 \mathrm{~m}$ buffered polygon area covered by roads was calculated as the area of the buffered polyline (including highway area if present) divided by the area of the buffered polygon after subtracting the area of the contained water body. We used linear regression to describe the relationship between total road area and population sex ratio.

\section{The effects of Bullfrogs on Average WPT Size/Age}

To quantify the effects of introduced predatory bullfrogs on hatchling and juvenile survival, we compared size distributions of WPT populations that do or do not have bullfrogs present. Given the anecdotal information supporting the negative impact of bullfrogs on WPT populations (e.g., Fig. 2), we focused on bullfrogs rather than other potential predators (largemouth bass, wading birds) because they are visible, sedentary predators and their presence is easily determined. However, we note that bullfrog presence is often highly correlated with other introduced predators including sunfish, bass, and crayfish (Fisher \& Shaffer, 1996; Madden-Smith et al. 2005; Riley et al., 2005; Miller et al., 2012), and distinguishing the specific effect of bullfrogs from other invasive species is impossible with observational data. For each contemporary data set that had at least 10 unique individual turtles, we calculated the average carapace length of the population for the most recent seven years, used a combination of published reports and personal communication with field biologists to confirm the presence or absence of bullfrogs at each site, and conducted t-tests (two tailed) on carapace lengths of sites with/without bullfrogs. One site in San Diego County that has undergone bullfrog eradication measures was treated as two sites, one for pre-eradication and one for post-eradication. For population sites where bullfrog observations were not available, we queried iNaturalist and recorded bullfrogs as present if a sighting had been recorded within one $\mathrm{km}$ of the WPT population site. 


\section{Results}

\section{Sex ratio changes through time}

296 Emys pallida

297 Based on the combined historical museum data and contemporary data sets (Fig. S3), the 298 probability of observing female specimens shifted from $\sim 0.5$ in 1900 to approximately 0.4 in 299 contemporary samples (Fig. 4, Hosmer and Lemeshow goodness of fit (GOF) test, $p=0.0005$ ).

300 The historical museum data alone show a similar, but non-significant decrease in the probability

301 of female specimens over time, while the contemporary data set indicates a slight but significant

302 increase in the probability of female captures (Fig. $4 ; \sim 0.4$ to $\sim 0.5$ ).

303

304

305

306

307

308

309

310

311

312

313

314

315

316

\section{Emys marmorata}

The trends in sex ratio probabilities over time in $E$. marmorata were similar to those in $E$ pallida. From the combined historical museum data and current data sets (Fig. 4), the overall probability of observing females in E. marmorata collections shifted from $\sim 0.5$ in 1900 to a more male-biased sex ratio of $\sim 0.4$ in contemporary populations (Fig. 4, Hosmer and Lemeshow goodness of fit (GOF) test, $p=0.0003$ ). The historical museum data and contemporary population surveys show similar trends over time (Fig. 4).

\section{Carapace Length}

\section{Emys pallida}

Mean carapace length of E. pallida remained relatively constant from 1892-2019 (significance test of linear regression, $p=0.43$ ) (Fig. 5). Museum samples $(1892-2005)$ considered alone showed a slight, but non-significant (significance test of linear regression, $p=$ .17) increase in carapace length over time (Fig. S5). Thus, there is no evidence that body size has been increasing as would be the case if there has been increasing juvenile mortality over time.

\section{Emys marmorata}

Unlike E. pallida, mean carapace length increased significantly in E. marmorata from 1894-2016 (significance test of linear regression, $p=<2.2 \mathrm{e}-16$ ) (Fig. 5). This trend holds with and without contemporary populations (museum specimens from 1892-2005, significance test of linear regression, $p=0.00056$, Fig. S6) suggesting that the trend is not solely a function of the recent population data. Together, the museum data and current data sets indicate that overall body size has been increasing in E. marmorata over the last century. 


\section{The Effects of Roads on Sex Ratio}

325

326

327

328

329

330

331

332

333

334

335

336

337

338

339

340

341

342

343

344

345

346

347

348

349

350

351

352

353

354

355

356

357

358

359

360

361

362

We pooled both species of WPT for our more detailed examination of road mortality as a cause of male-biased sex ratios. We did so for two reasons. First, no studies have indicated that the two species differ in the distance females travel from a body of water to nest, although this is admittedly a very understudied aspect of WPT biology (but see Brehme et al., 2018). Second, the number of population samples available for each species was relatively small, and pooling both taxa allowed us greater statistical power to detect trends.

When pooled across all sites and distances, the sex ratio of WPT populations showed a negative, but non-significant relationship to distance to the nearest road (significance test of linear regression, $p=0.13$, Fig. S7). However, visual inspection suggested that there was a shift toward less female-biased sex ratios when the closest road was approximately 250 meters or more distant from the centroid of the body of water (Fig. S7). To quantitatively explore the existence and location of a sex-ratio shift in the data, we conducted a "sliding-scale t-test" for the 19 population samples in our analysis. We first tested for a significant difference in the sex ratio of the two populations closest to roads (we refer to this as the road-proximate set of sites) compared to the 17 more distant sites. We then added the third closest site to the road-proximate set and performed a new t-test; we iteratively continued until the sex ratio of the road-proximate set differed from the remaining more distant populations. We found that the shift in significance occurred at 219 meters from the centroid of the body of water (Table S2). Sites where the nearest road was closer than 219 meters were significantly more male biased (average sex ratio $\sim 1.64$ ) than those more distant from the nearest road, which were tightly clustered around an even sex ratio (Fig. 6, two tailed t-test, $p=0.017$ ).

Road density within a biologically reasonable buffer may be a more important indicator of potential vehicular mortality than simply distance to the nearest road. The sex ratio of WPT populations became increasingly male biased as the proportion of land covered by roads within 400 meters of a water body increased, explaining $27 \%$ of the variance in adult sex ratio (Fig. 7, significance test of linear regression, $p=0.023$ ).

\section{The Effects of Bullfrogs on body size distribution}

We also pooled the bullfrog data for both species of WPT. We found a significant difference (two-tailed t-test, $\mathrm{df}=30.525, p=0.00040$ ) between the average carapace length of population sites with bullfrogs co-occurring and population sites without bullfrogs (Fig. 8). Population sites with bullfrogs present had an average carapace length of $148 \mathrm{~mm}$, while those without this introduced predator had an average carapace length of $122 \mathrm{~mm}$ (Fig. 8). However, there is a potential confounding factor caused by pooling the two WPT species because $E$. marmorata individuals are typically larger than E. pallida (Fig. 5). When conducted for each species separately, we found the same general trend in both species. Sites with bullfrogs had higher mean carapace length and fewer smaller individuals, and this trend was significant for both E. pallida (two-tailed t-test, $p=0.0444$ ) and $E$ marmorata (two-tailed t-test, $p<0.004$, Fig. S8, S9). 


\section{Discussion}

364 As a group, turtles are arguably the most threatened "major" vertebrate clade, with 52 -

$36561 \%$ of modern turtle species threatened or already extinct (Turtle Taxonomy Working Group,

366 2017; Lovich et al., 2018; Rhodin et al., 2018). Most turtle species are long-lived; our study taxa,

367 the two species of WPT, live to 45 years (Holland, 1994), and female-biased adult mortality,

368 with or without reduced recruitment, can have devastating consequences for long-lived species.

369 Multiple studies have observed or proposed that male-biased populations result in population

370 declines or extirpations of freshwater turtles (Ceballos et al., 2016; Vanek \& Glowacki, 2019),

371 and a long-term study of two wood turtle (Glyptemys insculpta) populations in Connecticut, USA

372 documented sharp declines coinciding with human-mediated reductions in adult females (Garber

373 \& Burger, 1995). Reduced juvenile production, the ultimate result of increased female mortality,

374 has also been found to result in freshwater turtle population declines or extirpations (Burgin and

375 Ryan, 2008; Howey \& Dinkelacker, 2013). Such populations may persist for years, but they do

376 so as part of the "living dead" (Lovich et al., 2018) that often characterize declining, long-lived

377 species.

378 No published study has quantitatively examined these demographic issues for the WPT.

379 We found that contemporary populations of both E. pallida and E. marmorata tend to be male

380 biased. Because turtles, including the WPT, exhibit temperature-dependent sex determination, a

381 conservation concern for many species is increasingly female biased sex ratios associated with

382 climate warming. Christie and Geist (2017) demonstrated that E. marmorata from Lake County,

383 CA had typical temperature-dependent sex determination for emydid turtles, with higher

384 temperatures producing female-biased clutches, and that from 2009-2012 natural nests incubated

385 in the wild produced $69 \%$ female hatchlings. Although only a single study, their work suggests

386 that temperature increases from human-mediated climate change should be producing female-

387 biased WPT primary sex ratios. If this is the case, the male bias that we document represents an

388 even more severe increase in post-hatching female mortality than if the primary sex ratio were

389 even.

$390 \quad$ Our results are less clear on changes in sex ratio over the last century. Our historical

391 analysis of sex ratios is based on museum data, and these collections can be biased in many,

392 sometimes subtle ways. Museum data may be biased if one sex or size class is more easily or

393 commonly collected (Gibbs \& Steen, 2005), as might occur in sexually or ecologically

394 dimorphic taxa, or if collections come from different regions at different points in time (Shaffer

395 et al., 1998). In our case, the museum data were drawn from across the range of both species

396 (Fig. 1), which eliminates some bias that can occur with more limited sampling. Because female

397 turtles spend more time on land than males and are therefore more vulnerable to incidental

398 capture by museum scientists, any ecological bias should favor females over males, acting

399 against the observed male bias in most collections. Fortunately, the sex ratios in contemporary

400 population studies are based on aquatic trapping and hand-capture/snorkeling, both of which

401 should be unbiased with respect to gender.

$402 \quad$ Assuming that museum and contemporary data represent relatively unbiased sampling

403 efforts, both E. pallida and E. marmorata show a clear shift from essentially $1: 1$ in the early $20^{\text {th }}$

404 century to male biased in contemporary samples. However, the sex ratio trends of E. pallida and

405 E. marmorata differ in the last 20 years based on the current data sets (Fig. 4). While $E$.

406 marmorata shows an increase in male bias over the last two decades, E. pallida shows a slight

407 decrease in male bias. This may indicate that populations of E. pallida are returning to an even

Peer] reviewing PDF | (2019:10:42370:1:1:NEW 4 May 2020) 
408 sex ratio, although no plausible mechanisms have been suggested for such a shift. An alternative 409 explanation, first suggested by Madden-Smith et al. (2005) for parts of San Diego County, CA, is 410 a form of population filtering that may be driving this trend. Particularly in southern California, 411 where most recent population surveys have taken place, the remaining E. pallida sites are 412 relatively remote with restricted human access, while the species has been extirpated from most 413 areas with the high anthropogenic impact. These last remaining populations may have 414 experienced less impact than was historically typical for the species, leading to a trend reflecting 415 the survival, and monitoring, of an increasingly high proportion of viable populations. That is, 416 the trends seen in E. pallida may represent the sequential elimination of human-impacted sites, 417 rather than overall population recovery. Thus, while there are extant E. marmorata populations 418 which have experienced anthropogenic impact, the E. pallida populations most impacted by 419 humans have already been extirpated and those populations which remain are viable. Regardless 420 of the cause of differences in trends over the last 20 years, the two species are now quite similar, 421 and quite male-biased, in their sex ratios.

Our analyses provide strong, albeit correlational evidence that road proximity and density are associated with increasing male population bias. Our observation on the distance at which roads affect sex ratio matches closely with the distance females tend to travel from the water's edge, which ranges from a few meters up to a maximum of about $400 \mathrm{~m}$. For both species, populations within 220 meters of the closest road were male biased, while those further away were not (Fig. 6). Road density within 400m of a study site, which models the likelihood that female mortality occurs during nesting road encounters, explained $27 \%$ of the variation in population sex ratios; the fitted linear regression of sex ratio as a function of road density predicts that the expected sex ratio of a population will change from $1: 1$ in roadless areas to $2: 1$ when $\sim 7.5 \%$ of the area within $400 \mathrm{~m}$ is covered by road (Fig. 7). This is in contrast to previous studies which hypothesized that roads should not threaten small bodied pond turtles anywhere in the U.S. (Gibbs \& Shriver, 2002), but is consistent with a recent threat assessment focused on California road mortality risk across reptiles and amphibians (Brehme et al., 2018). Our analyses indicate that road density and proximity may lead to demographic changes of small bodied pond turtles like the WPT which could in turn drive population declines. Whether such changes are due to direct mortality from vehicles or the increased presence of human activity that roads inevitably incur is impossible to determine (Garber \& Burger, 1995); both are likely contributing factors. In either case, a combination of under-road tunnels, barrier fences, and even simple "turtle crossing" signage coupled with community education and outreach could be effective strategies to stem the mortality of gravid females seeking nesting sites. Many of these road mitigation strategies have already been proven to be effective for turtles. A study in Presqu'ile Provincial Park, Ontario, Canada, found that both barrier fences and under-road tunnels reduced road mortality of turtles (Boyle, 2019). Additional studies support the efficacy of both of these strategies. Barrier fences effectively reduced road mortality of diamondback terrapins in Cape May County, New Jersey (Ives-Dewey \& Lewandowski, 2012) as did under-road tunnels for painted turtles in Massachusetts (Paulson, 2010).

We also found a significant increase in carapace length over the last century in $E$. marmorata but not in E. pallida. Assuming that carapace length is a reasonable proxy for age, our results indicate that the average age of $E$. marmorata populations has increased over the last century while the average age of E. pallida has not. This is an unexpected difference, because we expected that the greater urbanization in the southern California range of E. pallida would result in decreased recruitment and overall population senescence. In fact, the opposite appears to be 
454 the case. This could indicate that E. pallida has not had reduced recruitment in recent years, 455 while E. marmorata has. Alternatively, the same "population filtering" discussed previously for 456 southern California contemporary population studies may be driving this pattern. As a recent 457 report indicates (Madden-Smith et al., 2005), non-native turtles and a large community of 458 invasive predators have now essentially replaced native WPT in accessible San Diego County coastal habitats, and the few locations where WPTs still persist are free of many invasive predators. Consistent with this interpretation, most of the current E. marmorata population studies co-occur with bullfrogs (8/10 sites had bullfrogs present) while only half of the contemporary E. pallida populations had bullfrogs present (8/15 sites). However, the range of $E$. pallida actually has more iNaturalist sightings of bullfrogs per square $\mathrm{km}$ (density of bullfrog sightings in the range of E. marmorata $=0.002$ bullfrogs $/ \mathrm{km}^{2}, E$. pallida $=0.008$ bullfrogs $/ \mathrm{km}^{2}$, $p=0.02$, two-tailed t-test) (Fig. S1). This is consistent with the interpretation that most of the impacted habitats in southern California with bullfrogs have already lost their pond turtles, and that the remaining E. pallida populations tend to be relatively remote sites without introduced predators. Although speculative, this line of reasoning suggests that invasive predator removal may be an important next step both in recovery of extant populations, and as a precursor to any WPT repatriation efforts.

\section{Conclusions}

472

473

474

475

476

477

478

479

480

481

482

483

484

485

486

487

488

489

490

491

\section{2}

493

494

Natural history collections provide important historical baselines, including demographic trends, that are critical for declining species management. Based on our analyses, both shifts toward male sex-ratio bias and reduced recruitment have occurred in E. marmorata, consistent with a long, slow decline in population health. While male sex-ratio bias has also occurred in E. pallida, our data do not indicate that reduced recruitment is an ongoing threat for currently extant populations. Ultimately, the joint analysis of natural history collections as historical data with contemporary published and unpublished data sets shared with us through personal communications with WPT field researchers (B Shaffer, P Scott, R Fisher, C Brown, R Dagit, L Patterson, T Engstrom, 2019, personal communications) allowed us to document demographic changes in both species which would have been otherwise impossible. Knowledge of these demographic changes provides important population trend information for current protections under consideration for both species. Our analyses indicate that roads and non-native predatory bullfrogs constitute significant threats to the long-term persistence of both species of western pond turtle. Fortunately, both of these threats are, in theory, reversible. In combination with ongoing threat analyses and PVAs for both species (Manzo et al., 2020), our results suggest that significant declines have occurred in both species, although the population health and stability of E. pallida is more fragile and in greater decline than E. marmorata. Our assessment of demographic changes and their underlying potential mechanisms emphasizes how natural history collections can complement contemporary data to help identify shifts in population demographics and potential causative anthropogenic impacts responsible for these shifts.

\section{Acknowledgements}

We thank all the field ecologists who provided data sets for our analyses including Tag Engstrom and Laura Patterson, and the USGS team that helped collect field data on turtles since the late 
1990's. We also thank the curatorial staff who gave us access to natural history collections and provided their time and assistance, including Greg Pauly (Los Angeles Natural History Museum), Carol Spencer (Museum of Vertebrate Zoology), and Lauren Scheinberg (California Academy of Sciences). Any use of trade, firm, or product names is for descriptive purposes only and does not imply endorsement by the U.S. Government.

\section{References}

Aresco MJ. 2005. The effect of sex-specific terrestrial movements and roads on the sex ratio of freshwater turtles. Biological Conservation 123: 37-44.

Babin-Fenske J, Anand M, Alarie Y. 2008. Rapid morphological change in stream beetle museum specimens correlates with climate change. Ecological Entomology 33(5): 646651.

Belli JP. 2015. Movements, habitat use, and demography of western pond turtles in an intermittent central California stream. MS Thesis, San José State University.

Boyle, SP. 2019. A road to conservation: understanding the dynamics of road-effects and roadeffect mitigation. $\mathrm{PhD}$ Thesis, Laurentian University.

Brehme CS, Hathaway SA, Fisher RN. 2018. An objective road risk assessment method for multiple species: ranking 166 reptiles and amphibians in California. Landscape Ecology 33: 911-935.

Burgin S, Ryan M. 2008. Comparison of sympatric freshwater turtle populations from an urbanized Sydney catchment. Aquatic Conservation-Marine and Freshwater Ecosystems 18(7): 1277-1284.

Bury BR, Whelan JA. 1984. Ecology and management of the bullfrog. United States Department of the Interior Fish and Wildlife Service Resource Publication 155.

Carstairs S, Dupuis-Desormeaux M, Davy CM. 2018. Revisiting the hypothesis of sex-biased turtle road mortality. Canadian Field Naturalist 132(3): 289-295.

Caruso NM, Sears MW, Adams DC, Lips KR. 2014. Widespread rapid reductions in body size of adult salamanders in response to climate change. Global Change Biology 20(6): 17511759.

Ceballos CP, Zapata D, Alvarado C, Rincón E. 2016. Morphology, diet, and population structure of the southern White-lipped Mud Turtle Kinosternon leucostomum postinguinale (Testudines: Kinosternidae) in the Nus River Drainage, Colombia. Journal of Herpetology 50(3): 374-380.

Christie NE, Geist NR. 2017. Temperature effects on development and phenotype in a free- 
538

539

540

541

542

543

544

545

546

547

548

549

550

551

552

553

554

555

556

557

558

559

560

561

562

563

564

565

566

567

568

569

570

571

572

573

574

575

576

577

578

579

580

581

582

583 living population of Western Pond Turtles (Emys marmorata). Physiological and Biochemical Zoology 90(1): 47-53.

Dorland A, Rytwinski T, Fahrig L. 2014. Do roads reduce painted turtle (Chrysemys picta) populations? PLoS ONE 9(5): e98414

ESRI. 2018. ArcGIS Release 10.6.1. Redlands, CA.

Fisher RN, Shaffer HB. 1996. The decline of amphibians in California's great Central Valley. Conservation Biology 10(5): 1387-1397.

Fritz U, Schmidt C, Ernst CH. 2011. Competing generic concepts for Blanding's, Pacific and European pond turtles (Emydoidea, Actinemys, and Emys) - Which is best? Zootaxa 2791: 41-53.

Garber SD, Burger J. 1995. A 20-Yr study documenting the relationship between turtle decline and human recreation. Ecological Applications 5(4): 1151-1162.

Germano DJ, Riedle JD. 2015. Population structure, growth, survivorship, and reproduction of Actinemys marmorata from a high elevation site in the Tehachapi Mountains, California. Herpetologica 71(2): 102-109.

Gibbs JP, Shriver WG. 2002. Estimating the effects of road mortality on turtle populations. Conservation Biology 16(6):1647-1652.

Gibbs JP, Steen DA. 2005. Trends in sex ratios of turtles in the United States: Implications of road mortality. Conservation Biology 19(2): 552-556.

Gogol-Prokurat, M. 2016. Western Pond Turtle Range - CWHR R004 [ds598]. Calif. Dept. of Fish and Wildlife. Biogeographic Information and Observation System (BIOS). Retrieved September 25, 2019 from http://bios.dfg.ca.gov

Govindarajulu P, Price WMS, Anholt BR. 2006. Introduced bullfrogs (Rana catesbeiana) in Western Canada: has their ecology diverged? Journal of Herpetology 40(2): 249-260.

Grixti JC, Wong LT, Cameron SA, Favret C. 2009. Decline of bumble bees (Bombus) in the North American Midwest. Biological Conservation 142(1): 75-84.

Hallock LA, McMillan A, Wiles GJ. 2017. Periodic status review for the Western Pond Turtle in Washington. Washington Department of Fish and Wildlife, Olympia, Washington. $19+\mathrm{v}$ pp.

Hamer AJ, Lane SJ, Mahony MJ. 2010. Using probabilistic models to investigate the disappearance of a widespread frog-species complex in high-altitude regions of southeastern Australia. Animal Conservation 13(3): 275-285.

Peer] reviewing PDF | (2019:10:42370:1:1:NEW 4 May 2020) 
584 Holland DC. 1991. A Synopsis of the ecology and status of the Western Pond Turtle (Clemmys

585

586

587

588

589

590

591

592

593

594

595

596

597

598

599

600

601

602

603

604

605

606

607

608

609

610

611

612

613

614

615

616

617

618

619

620

621

622

623

624

625

626

627

628

629

marmorata) in 1991. Report to National Ecological Research Center. United States Fish and Wildlife Service, San Simeon, California.

Holland DC. 1994. The Western Pond Turtle: Habitat and History. Wildlife Diversity Program, Oregon Department of Fish and Wildlife. 303 pp.

Howey CAF, Dinkelacker SA. 2013. Characteristics of a historically harvested Alligator Snapping Turtle (Macrochelys temminckii) Population. Copeia 2013(1): 58-63.

Iverson JB. 2018. How to measure a turtle. Herpetological Review 49(3): 453-460.

Ives-Dewey D, Lewandowski JP. 2012. Spatial patterns of road mortality: assessing turtle barrier conservation strategies. Middle States Geographer 45: 40-47.

Jancowski K, Orchard SA. 2013. Stomach contents from invasive American bullfrogs Rana catesbeiana (= Lithobates catesbeianus) on southern Vancouver Island, British Columbia, Canada. NeoBiota 16: 17-37.

Lacy RC. 2000. Structure of the VORTEX simulation model for population viability analysis. Ecological Bulletins 48: 191-203.

Lambert MR, McKenzie JM, Screen RM, Clause AG, Johnson BJ, Mount GG, Shaffer HB, Pauly GB. 2019. Experimental removal of introduced slider turtles offers new insight into competition with a native, threatened turtle. PeerJ 7:e7444.

Lovich J, Meyer K. 2002. The western pond turtle (Clemmys marmorata) in the Mojave River, California, USA: highly adapted survivor or tenuous relict? Journal of Zoology, London 256: 537-545.

Lovich JE, Puffer SR, Cummings KL, Greely S. 2017. Feasibility study for re-establishing southwestern pond turtles and Mojave tui chubs to Afton Canyon ACEC. A Cooperator Report to the Bureau of Land Management under IAA No. L16PG00229. 43 pp.

Lovich JE, Ennen JR, Agha M, Gibbons JW. 2018. Where have all the turtles gone, and why does it matter? BioScience 68(10):771-781.

Madden-Smith MC, Ervin EL, Meyer KP, Hathaway SA, Fisher RN. 2005. Distribution and status of the Arroyo Toad (Bufo californicus) and Western Pond Turtle (E. marmorata) in the San Diego MSCP and surrounding areas. USGS Final Report. 183 plus $i$-iiv pages.

Major RE, Parsons H. 2010. What do museum specimens tell us about the impact of urbanisation? A comparison of the recent and historical bird communities of Sydney. EMU 110(1): 92-103.

Manzo S, Nicholson EG, Devereux Z, Fisher RN, Brown CW, Scott P, Shaffer HB. 2020.

Peer] reviewing PDF | (2019:10:42370:1:1:NEW 4 May 2020) 
630

631

632

633

634

635

636

637

638

639

640

641

642

643

644

645

646

647

648

649

650

651

652

653

654

655

656

657

658

659

660

661

662

663

664

665

666

667

668

669

670

671

672

673

674

675

Quantifying threats to the western pond turtle (Emys marmorata and Emys

pallida). Journal of Fish and Wildlife Management. Manuscript in preparation.

Marchand MN, Litvaitis JA. 2004. Effects of habitat features and landscape composition on the population structure of a common aquatic turtle in a region undergoing rapid development. Conservation Biology 18(3): 758-767.

McCarthy MA, Burgman MA, Ferson S. 1995. Sensitivity analysis for models of population viability. Biological Conservation 73(2): 93-100.

Miller DAW, Brehme CS, Hines JE, Nichols JD, Fisher RN. 2012. Joint estimation of habitat dynamics and species interactions: disturbance reduces co-occurrence of non-native predators with an endangered toad. Journal of Animal Ecology 81: 1288-1297.

Paulson, DJ. 2010. Evaluating the effectiveness of road passage structures for freshwater turtles in Massachusetts. MS Thesis, University of Massachusetts Amherst.

Polo-Cavia N, Engstrom T, Lopez P, Martin J. 2010. Body condition does not predict immunocompetence of western pond turtles in altered versus natural habitats. Animal Conservation 13: 256-264.

Pyke GH, Ehrlich PR. 2010. Biological collections and ecological/environmental research: a review, some observations and a look to the future. Biological Reviews 85(2): 247-266.

R Core Team. 2019. R: A language and environment for statistical computing. $R$ Foundation for Statistical Computing, Vienna, Austria.

R Studio Team. 2018. RStudio: Integrated Development for R. RStudio, Inc., Boston, MA.

Rhodin AGJ, Stanford CB, van Dijk PP, Eisemberg C, Luiselli L, Mittermeier RA, Hudson R, Horne BD, Goode EV, Kuchling G, Walde A, Baard EHW, Berry KH, Bertolero A, Blanck TEG, Bour R, Buhlmann KA, Cayot LJ, Collett S, Currylow A, Das I, Diagne T, Ennen JR, Forero-Medina G, Frankel MG, Fritz U, García G, Gibbons JW, Gibbons PM, Gong S, Guntoro J, Hofmeyr MD, Iverson JB, Kiester AR, Lau M, Lawson DP, Lovich JE, Moll E, Páez VP, Palomo-Ramos R, Platt K, Platt SG, Pritchard PCH, Quinn HR, Rahman SC, Randrianjafizanaka ST, Schaffer J, Selman W, Shaffer HB, Sharma DSK, Shi H, Singh S, Spencer R, Stannard K, Sutcliffe S, Thomson S, Vogt RC. 2018. Global conservation status of turtles and tortoises (order Testudines). Chelonian Conservation and Biology 17: 135-161.

Riley SPD, Busteed GT, Kats LB, Vandergon TL, Lee LFS, Dagit RG, Kerby JL, Fisher RN, Sauvajot RM. 2005. Effects of urbanization on the distribution and abundance of amphibians and invasive species in southern California streams. Conservation Biology 19: 1984-1907.

Saarinen EV, Daniels JC. 2012. Using museum specimens to assess historical distribution and

Peer) reviewing PDF | (2019:10:42370:1:1:NEW 4 May 2020) 
676

677

678

679

680

681

682

683

684

685

686

687

688

689

690

691

692

693

694

695

696

697

698

699

700

701

702

703

704

705

706

707

708

709

710

711

712

713

714

715

716

717

718

719

720

721

genetic diversity in an endangered butterfly. Animal Biology 62(3): 337-350.

Shaffer HB, Fisher RN, Davidson C. 1998. The role of natural history collections in documenting species declines. Tree 13(1): 27-30.

Sloan LM. 2012. Population structure, life history, and terrestrial movements of Western Pond Turtles (Actinemys marmorata) in lentic habitats along the Trinity River, California. MS Thesis, Humboldt State University.

Smith JJ. 2018. Aquatic sampling at Canada de los Osos Reserve in 2013-2018. San Jose State University. $45 \mathrm{pp}$.

Spellerberg IF. 1998. Ecological effects of roads and traffic: a literature review. Global Ecology and Biogeography Letters 7: 317-333.

Spinks PQ, Pauly GB, Crayon JJ, Shaffer HB. 2003. Survival of the Western Pond Turtle (E. marmorata) in an urban California environment. Biological Conservation 113(2): 257267.

Spinks PQ, Thomson RC, Shaffer HB. 2014. The advantages of going large: genome-wide SNPs clarify the complex population history and systematics of the threatened western pond turtle. Molecular Ecology 23(9): 2228-2241.

Spinks PQ, Thomson RC, McCartney-Melstad E, Shaffer HB. 2016. Phylogeny and temporal diversification of the New World pond turtles (Emydidae). Molecular Phylogenetics and Evolution 103: 85-97.

Steen DA, Gibbs JP. 2004. Effects of roads on the structure of freshwater turtle populations. Conservation Biology 18(4):1145-1148.

Storer TI. 1930. Notes on the range and life-history of the Pacific Fresh-Water Turtle, Clemmys marmorata. University of California Publications in Zoology 32(5): 429-441.

Thomson RC, Wright AN, Shaffer HB. 2016. California Amphibian and Reptile Species of Special Concern. California Department of Fish and Wildlife, Sacramento, California.

Turtle Taxonomy Working Group [Rhodin AGJ, Iverson JB, Bour R, Fritz U, Georges A, Shaffer HB, van Dijk PP]. 2017. Turtles of the World: Annotated checklist and atlas of taxonomy, synonymy, distribution, and conservation status (8th Ed.). In: Rhodin AGJ, Iverson JB, van Dijk PP, Saumure RA, Buhlmann KA, Pritchard PCH, Mittermeier RA (Eds.). Conservation Biology of Freshwater Turtles and Tortoises: A Compilation Project of the IUCN/SSC Tortoise and Freshwater Turtle Specialist Group. Chelonian Research Monographs 7:1-292. doi: 10.3854/crm.7.checklist.atlas.v8.2017.

U.S. Department of Transportation Federal Highway Administration. 2013. Code of Federal Regulations, 23 CFR 625. Chapter 3: The 13 Controlling Criteria. 
722

723

724

725

726

727

728

729

730

731

732

733
U.S. Fish and Wildlife Service. 2015. Endangered and threatened wildlife and plants; 90-day findings on 10 Petitions. Federal Register 80(69): 19259 - 19263.

Vanek JP, Glowacki GA. 2019. Assessing the impacts of urbanization on sex ratios of Painted Turtles (Chrysemys picta). Diversity 11(72):1-13

Weeks BC, Willard DE, Zimova M, Ellis AA, Witynski ML, Hennen M, Winger BM. 2019. Shared morphological consequences of global warming in North American migratory birds. Ecology Letters. 
Figure 1

WPT museum specimens included in this study.

Collection dates range from 1892-2005. Species ranges from Gogol-Prokurat, 2016 (for California), USGS Gap Analysis Project, 2017 (for Oregon and Washington), and SDNHM HerpAtlas, 2014 (for Baja California, Mexico).

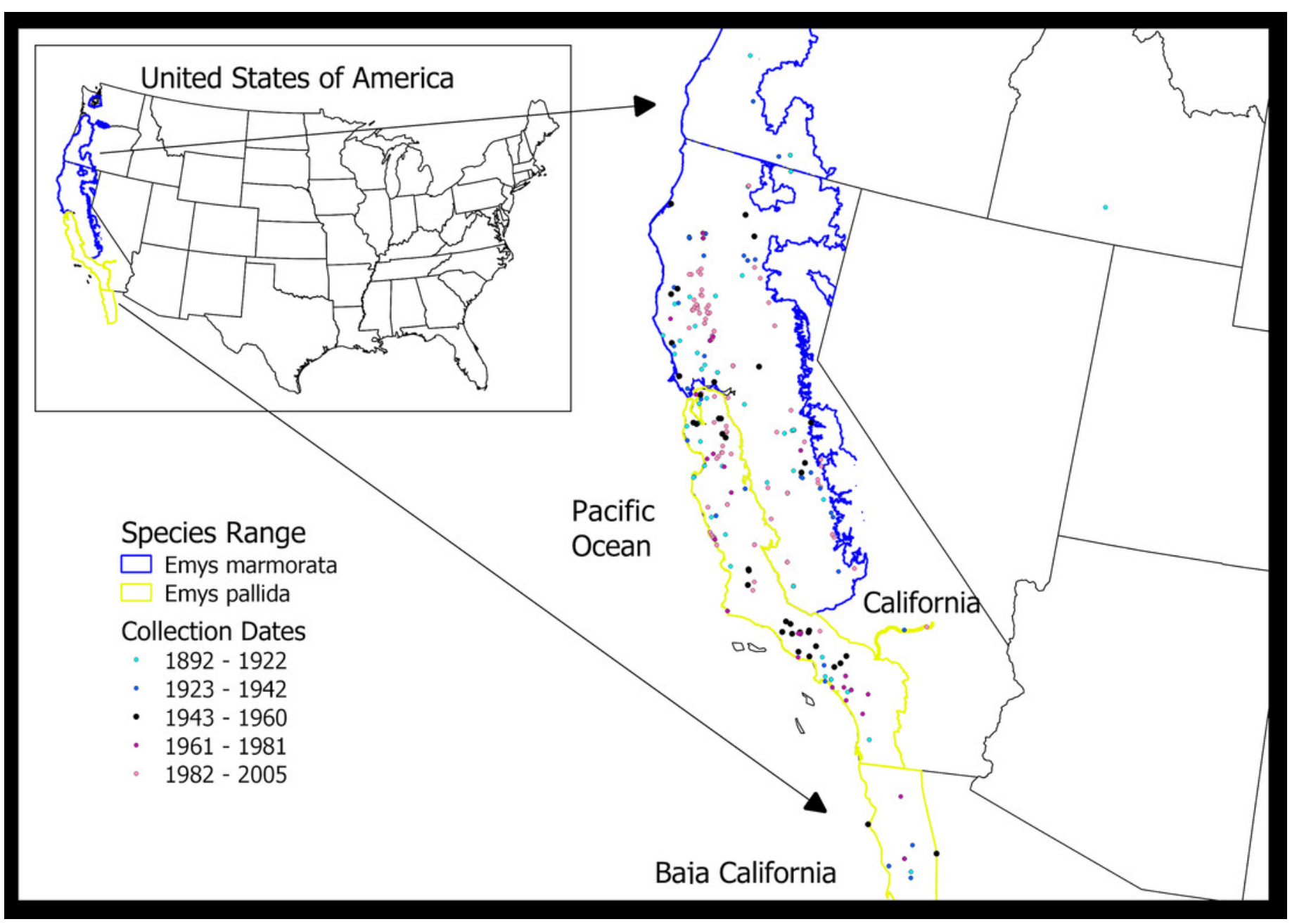




\section{Figure 2}

Hatchling western pond turtle found in the stomach of a bullfrog in the San Luis Rey River, San Diego Co. USA

(Source - U.S. Geological Survey, Western Ecological Research Center, San Diego, CA, USA)

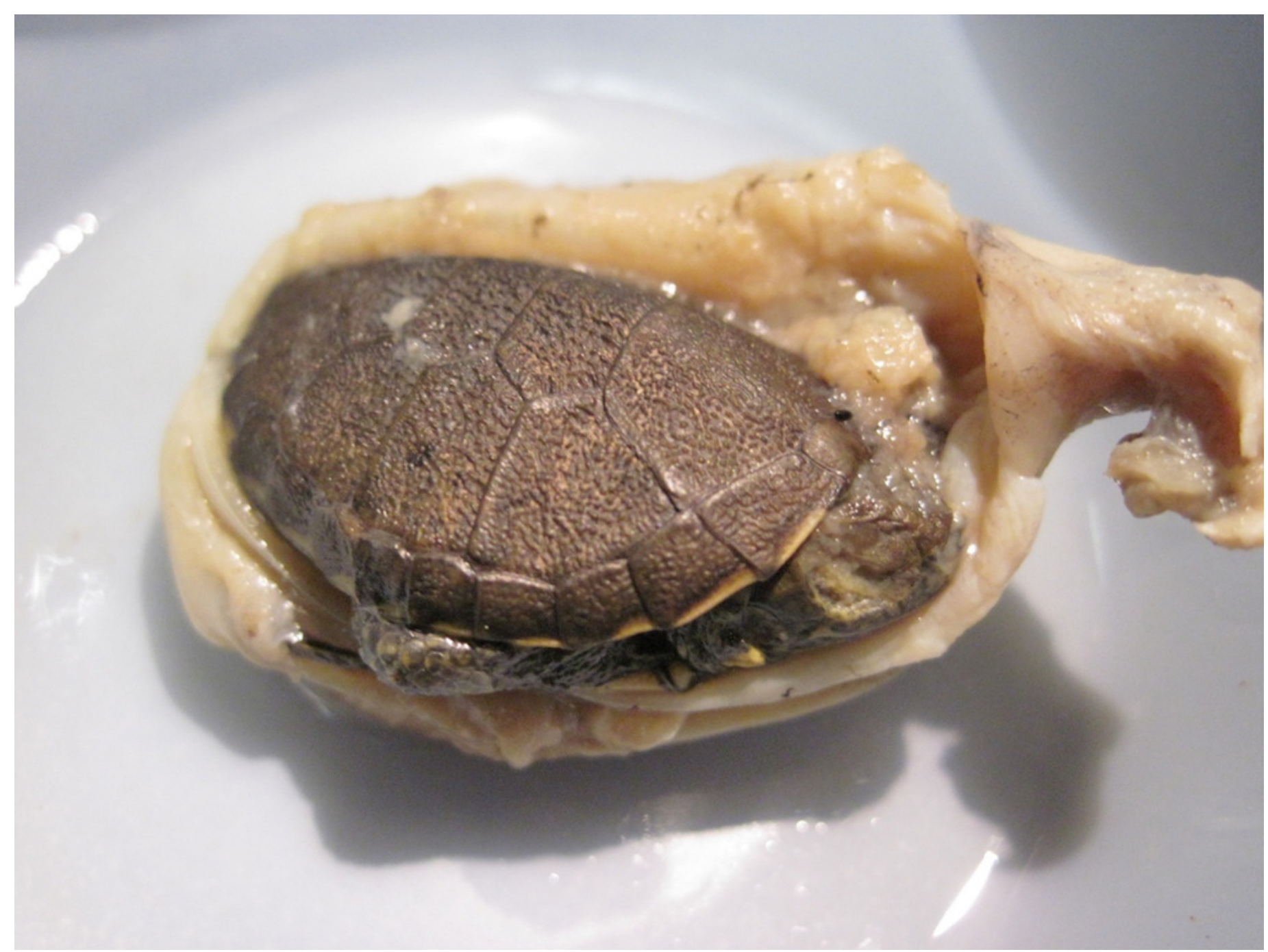


Figure 3

WPT contemporary population samples collected between 2002 - 2019.

(Sources: R Fisher \& C Brown, 2019, personal communications; R Dagit, 2019, personal communication; B Shaffer, 2019, personal communication; B Shaffer \& P Scott, 2019, personal communications; T Engstrom, 2019, personal communication; L Patterson, 2019, personal communication; Lambert et al., 2019)

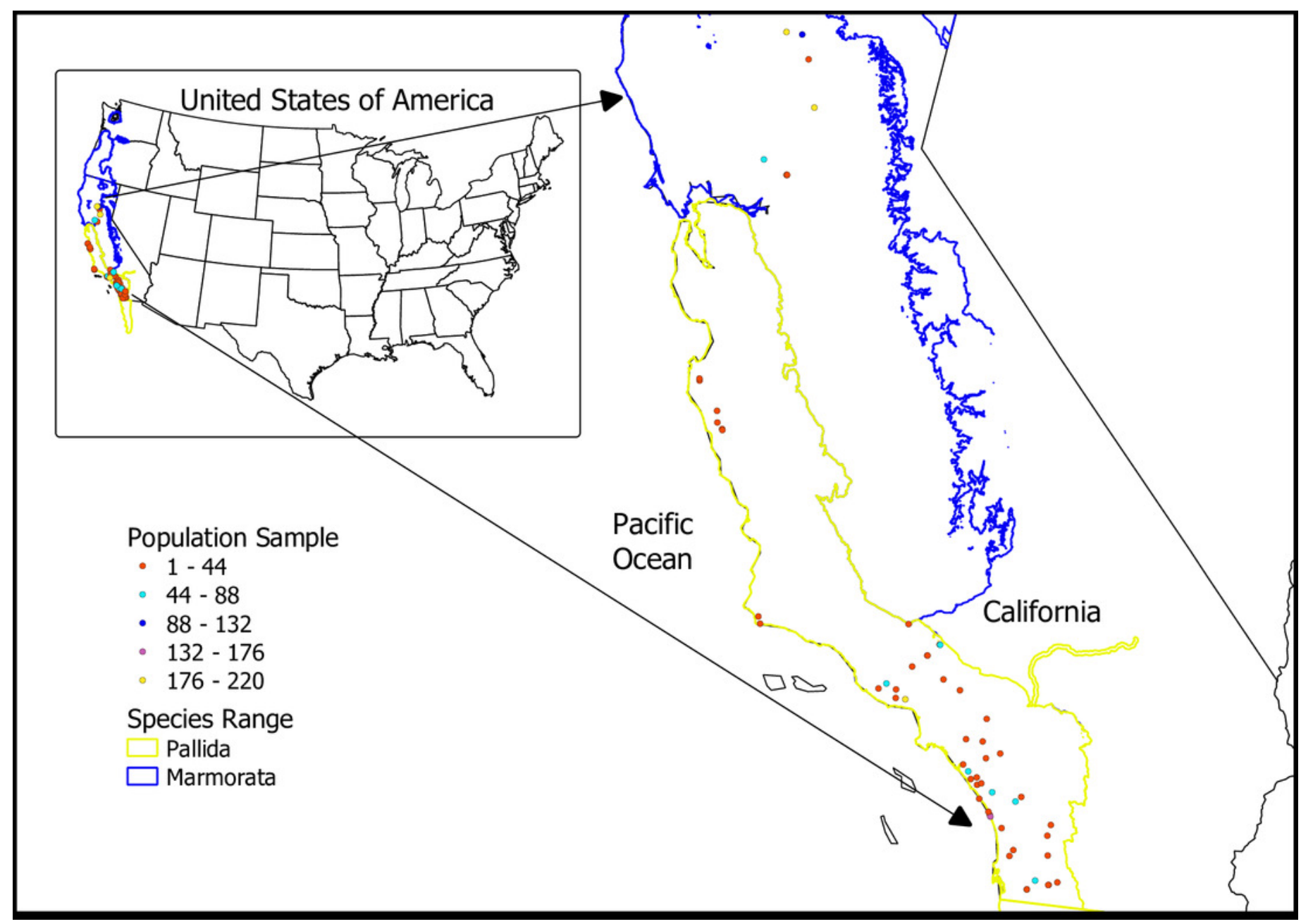




\section{Figure 4}

Logistic regressions of sex ratio for E. pallidaand E. marmorata.

Female WPTs were given the variable of 1 while male WPTs were given the variable of 0 . The sample sizes for each year are represented by gray circles which are proportional to the sample size for the year. a) Combined regression based on both the E. pallida museum and current samples (Hosmer and Lemeshow goodness of fit (GOF) test: X-squared $=27.871$, df $=8, p$-value $=0.0004994$ ). b) Regression based on the E. pallida museum samples (Hosmer and Lemeshow goodness of fit (GOF) test: $X$-squared $=11.625, d f=8, p$-value $=0.1687$ ). c) Regression based on the current $E$. pallida samples (Hosmer and Lemeshow goodness of fit (GOF) test: $X$-squared $=19.911, d f=8, p$-value $=0.01068)$. $d$ ) Combined regression based on both the E. marmorata museum and current samples (Hosmer and Lemeshow goodness of fit (GOF) test: $X$-squared $=29.457, \mathrm{df}=8, \mathrm{p}$-value $=0.0002636$ ). e) Regression based on the E. marmorata museum samples (Hosmer and Lemeshow goodness of fit (GOF) test: $X$ squared $=2.6945, \mathrm{df}=8, \mathrm{p}$-value $=0.952 . \mathrm{f})$ Regression based on the current $E$. marmorata samples (Hosmer and Lemeshow goodness of fit (GOF) test: $X$-squared $=32.3, \mathrm{df}=8, \mathrm{p}$ value $=8.299 \mathrm{e}-05)$. 

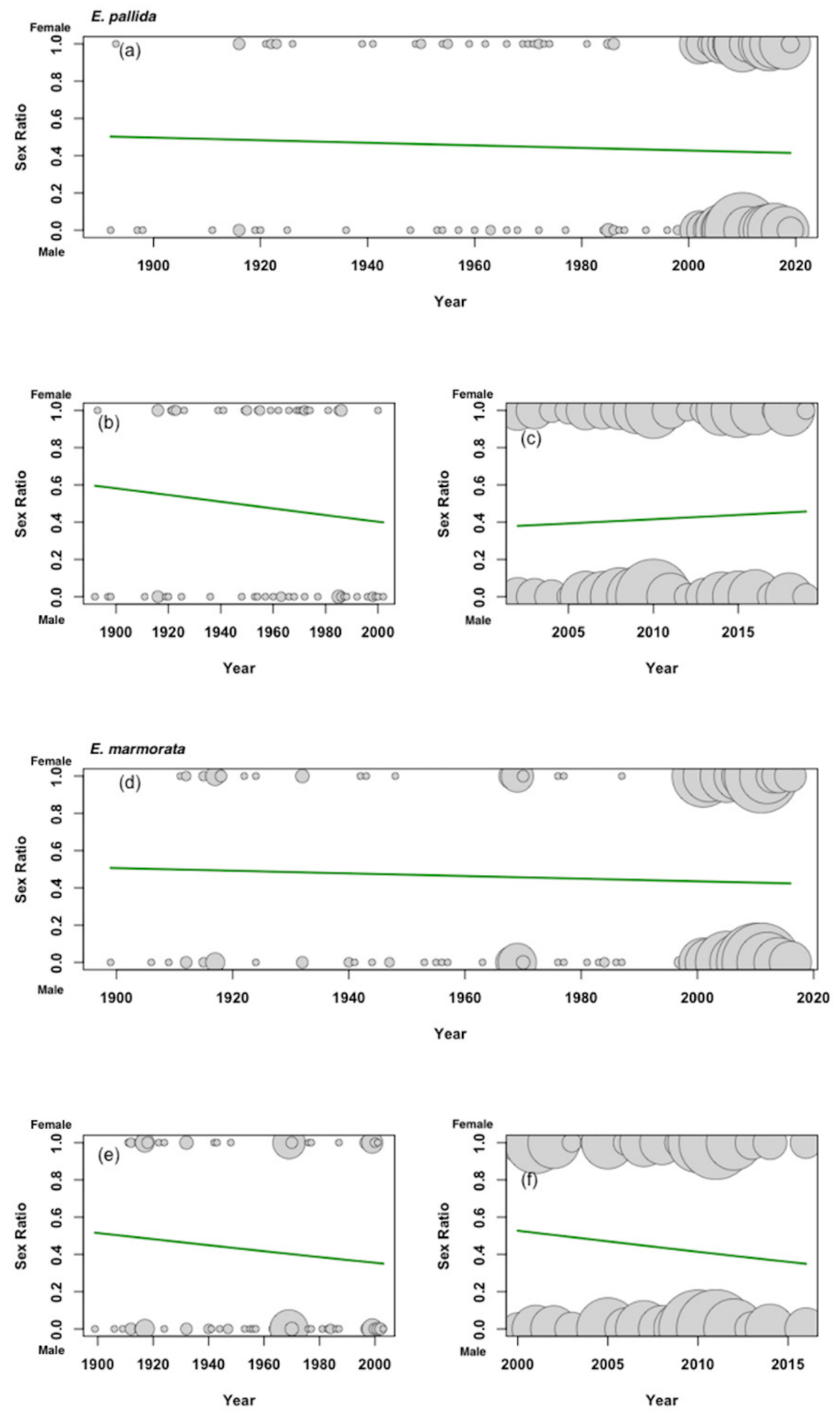

Peer] reviewing PDF | (2019:10:42370:1:1:NEW 4 May 2020) 
Figure 5

Plots of midline carapace lengths vs. time for A) E. pallida from 1892-2019 ( $\mathrm{n}=2095$, Adjusted R-Squared $=-0.0001874, p=0.43$ ) and for $B$ ) $E$. marmorata from 1894-2016 ( $=1697$, Adjusted R-Squared $=0.13, p=<2.2 \mathrm{e}-16$ ).

The blue trend lines and grey shading show the linear regressions and $95 \%$ confidence intervals for the slopes of the lines. 


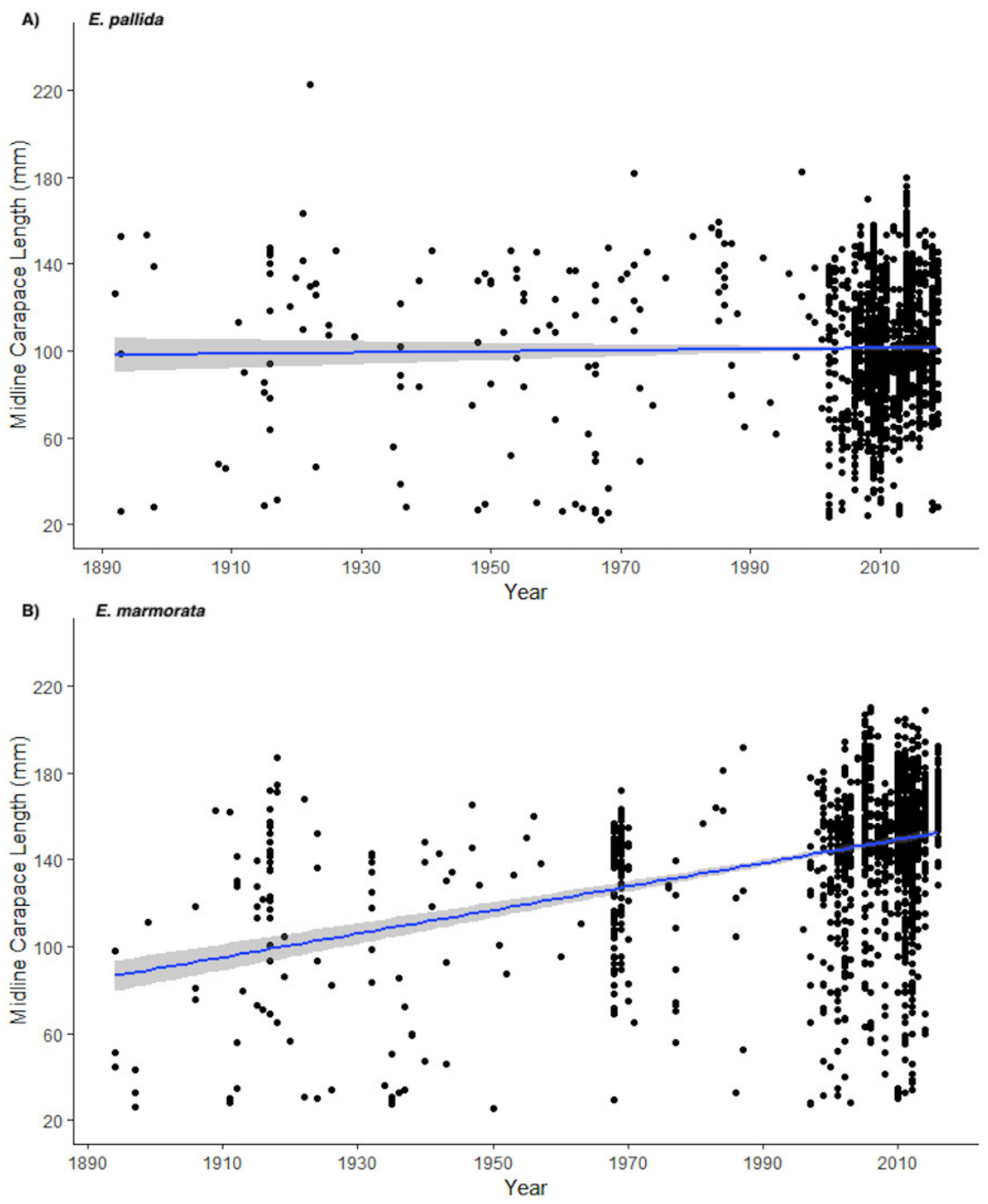




\section{Figure 6}

Plotted comparison of the sex ratios (Male: Female) of WPT population sites with the nearest road under 220 meters away with sites with the nearest road over 220 meters away ( $\mathrm{n}=13$ for under $220 \mathrm{~m}, \mathrm{n}=6$ for over $220 \mathrm{~m}, \mathrm{p}=0.016909056$ ).

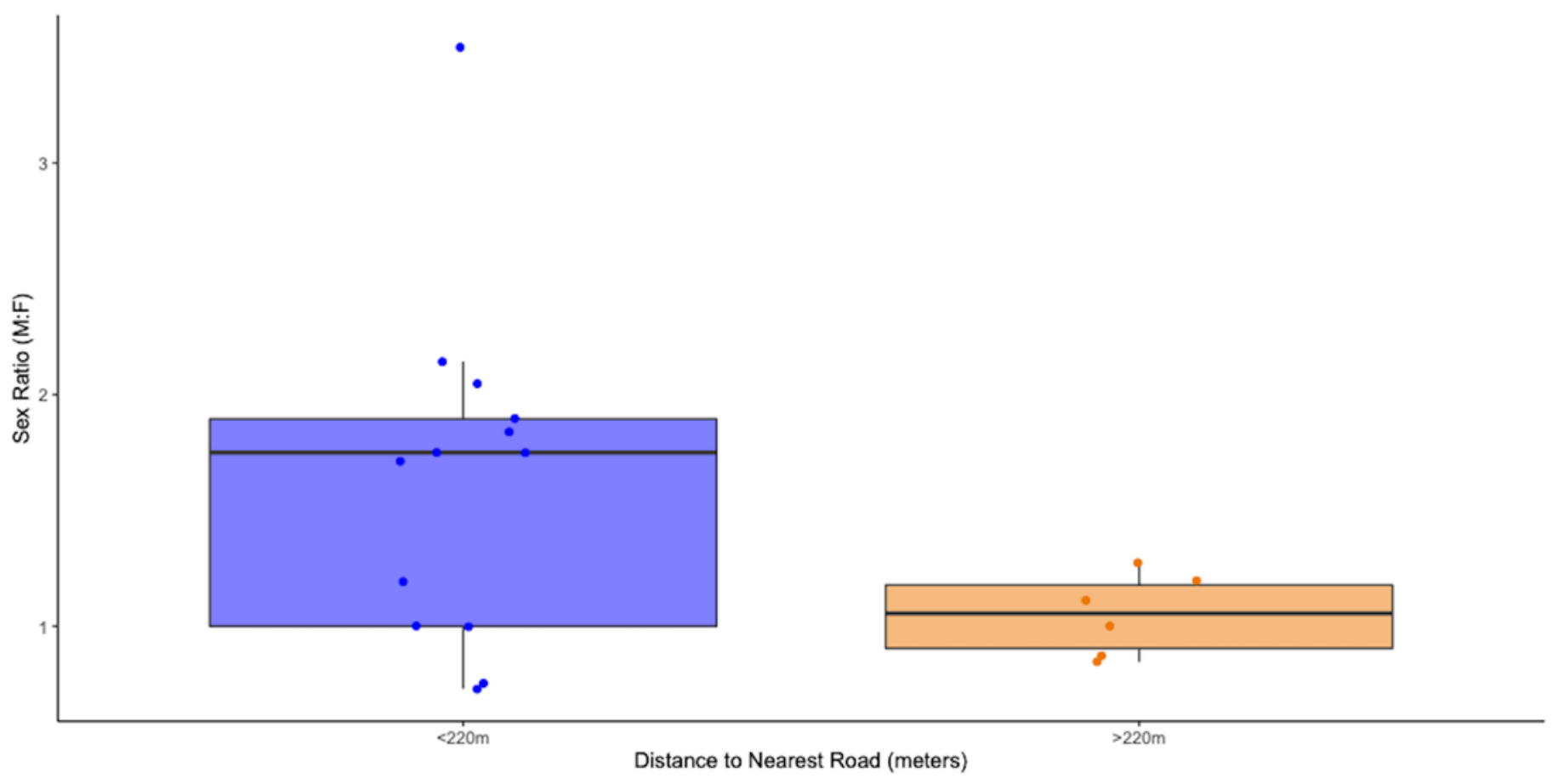


Figure 7

Plot of sex ratio (Male: Female) vs. proportion of land cover within 400 meters of a WPT population site that was roadway $(n=19, \mathrm{R}$-squared $=0.2698, p=0.022663)$.

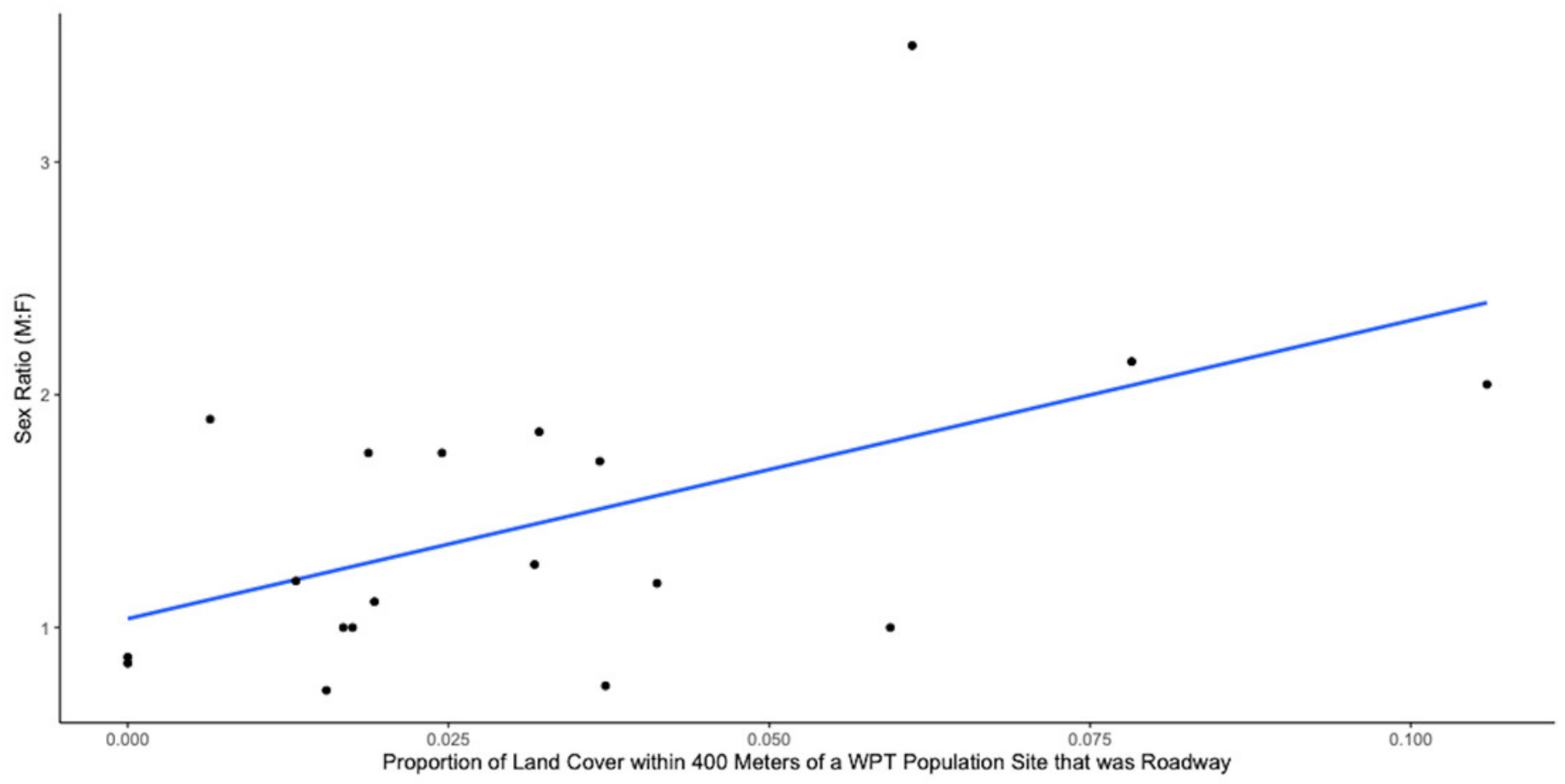




\section{Figure 8}

Average carapace lengths ( $\mathrm{mm}$ ) of WPT population sites with bullfrogs absent $(n=18)$ and present $(n=16)$ pooled across $E$. marmorata and E. pallida.

The difference is significant (two-tailed t-test, $p=0.00039337$ )

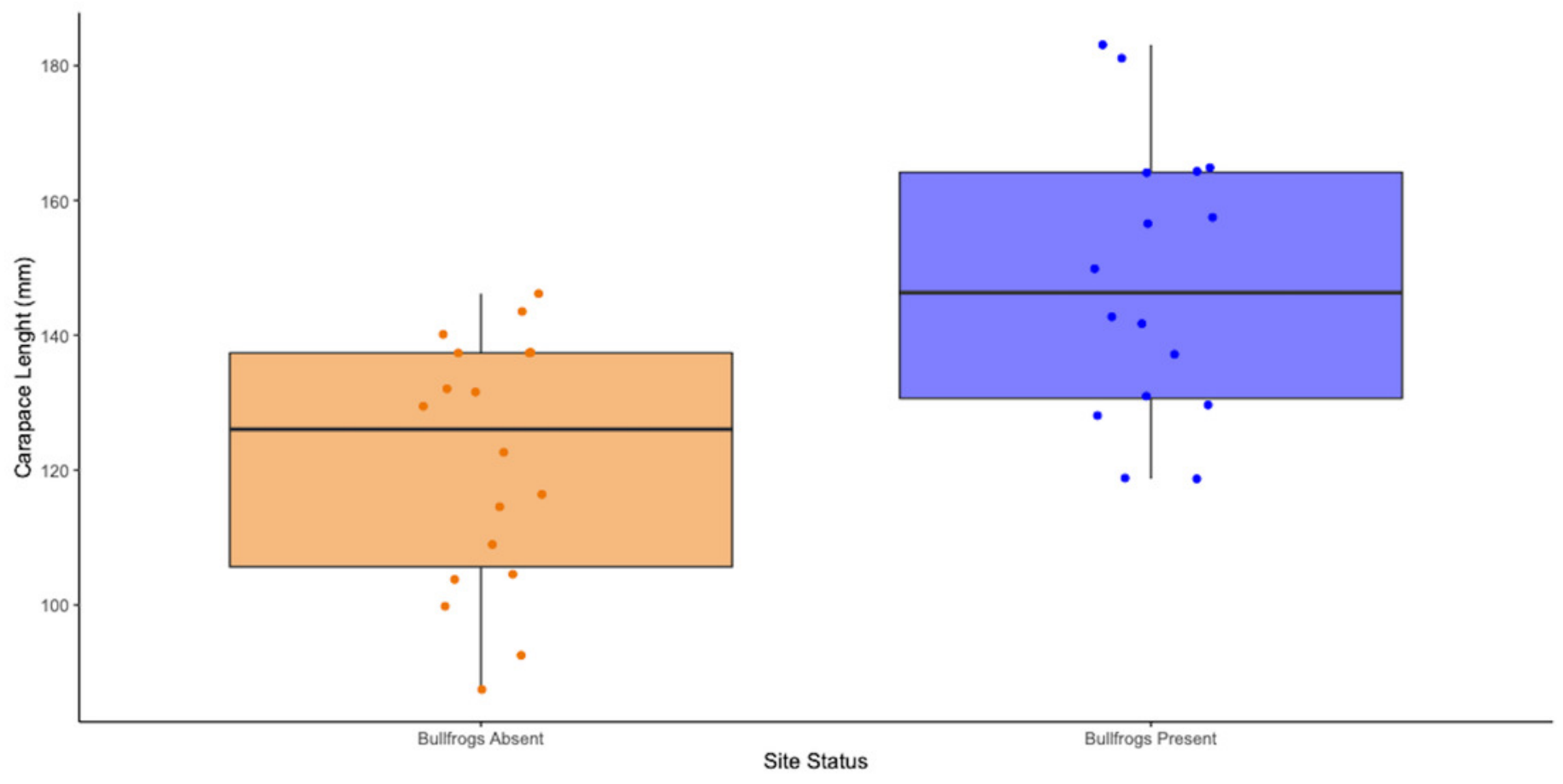

